\title{
Research on China's Rural Development Strategy Based on SWOT-AHP Analysis
}

\author{
Xianfeng Guo ${ }^{1}$, Han Yan $^{1} \&$ Wei Yuan ${ }^{1}$ \\ ${ }^{1}$ Sichuan Administration Institute, Chengdu, China \\ Correspondence: Wei Yuan, Sichuan Administration Institute, Chengdu 610072, Sichuan, China.
}

Received: April 10, 2019

Accepted: April 28, 2019

Online Published: May 5, 2019

doi:10.20849/iref.v3i1.571

URL: https://doi.org/10.20849/iref.v3i1.571

\begin{abstract}
The rapid urbanization development has helped China's economy to rise sharply, and it has also plunged the countryside into a development dilemma. Based on a questionnaire survey of 25 industry experts, this paper uses SWOT-AHP analysis to study the advantages, disadvantages, opportunities and threats of rural development, and finally determines the development strategy of rural China. Put forward three suggestions on rural development in China, that is, grasp the national strategic opportunity to develop modern agriculture, upgrade the level of rural human capital and cultivate the concept of ecological civilization.
\end{abstract}

Keywords: Analytic Hierarchy Process (AHP), SWOT analysis, rural development, modern agriculture

\section{Background}

China is in the process of rapid industrialization and urbanization. According to the statistical bulletin of the National Bureau of Statistics in 2018, China's urbanization level has reached 59.58\%, and is expected to reach 60 percent by 2020 . China currently has about 40,000 towns, 700,000 administrative villages and 2.7 million natural villages (Note 1). Since the 1990s, China's rural areas have gradually lost their vitality, especially in the western regions. The decline of rural areas is an indisputable objective fact.

But the countryside plays an extremely important role in the country's development. It provides raw materials for urban production and agricultural products for urban life. At the same time, it also inherits the long history of the country. Even in countries with high urbanization rates, there is still a need for rural existence. For example, the German village is known as the "fairy world" and the English countryside is called the "national soul". For China, even if the urbanization rate reaches $60 \%$, more than 400 million people still live in the countryside. Therefore, the revival and prosperity of the countryside is an inevitable requirement of China's modernization.

\section{China's Rural Development Strategy Goal - Modernization}

Modernization reveals the trend, direction and path of human society towards civilization. It is a comprehensive process of social progress, covering many levels, such as productivity, production relations, superstructure, involving many fields, such as politics, economy, society, humanities, system, science and technology. Modernization promotes social development in the process of "innovation - choice - elimination". China, including the Chinese countryside, also hopes to achieve modernization. Rural modernization consists of three elements: urbanization construction based on rural modernization, modern agricultural industrial park construction based on agricultural modernization, and rural comprehensive construction based on agriculture and rural modernization.

\section{Using SWOT-AHP to Analyze Rural Development in China}

This paper designs indicators from the strengths, weaknesses, opportunities and threats that have certain influence on China's rural development. It follows the SWOT-AHP framework to conduct qualitative and quantitative analysis to explore the future development choices of China's rural areas.

\subsection{SWOT Analysis}

China's rural sustainable development may face internal advantages and development opportunities, as well as disadvantages and threats. The details are shown in Table 1. 
Table 1. SWOT analysis of rural development in China

\begin{tabular}{|c|c|c|}
\hline \multirow[t]{4}{*}{ Internal Factors } & $\mathbf{S}$ & $\mathbf{W}$ \\
\hline & $\begin{array}{l}\text { S1: Excellent } \\
\text { environment and rich natural } \\
\text { resources. }\end{array}$ & $\begin{array}{l}\text { W1: Development of modern } \\
\text { agriculture is sluggish, economic } \\
\text { structure changes lag. }\end{array}$ \\
\hline & $\begin{array}{l}\text { S2: Rural civilization with a long } \\
\text { history. }\end{array}$ & \multirow{2}{*}{$\begin{array}{l}\text { W2: The rural environment is } \\
\text { prominent and the population is } \\
\text { hollow. } \\
\text { W3: The agricultural labor force has } \\
\text { a low level of human capital, and it is } \\
\text { difficult for farmers to increase their } \\
\text { income. }\end{array}$} \\
\hline & $\begin{array}{l}\text { S3: Great potential for rural } \\
\text { economic development. }\end{array}$ & \\
\hline \multirow[t]{5}{*}{ External Factors } & $\mathbf{O}$ & $\mathbf{T}$ \\
\hline & $\begin{array}{l}\text { O1: The country's comprehensive } \\
\text { strength has increased, and the } \\
\text { government has formulated a " }\end{array}$ & \multirow{4}{*}{$\begin{array}{l}\text { T1: The international competition } \\
\text { that agriculture faces is more and } \\
\text { more intense. } \\
\text { T2: China's slowing economic } \\
\text { growth has had a big impact on } \\
\text { farmers' incomes. }\end{array}$} \\
\hline & rural revitalization strategy". & \\
\hline & $\begin{array}{l}\text { O2: The tremendous development } \\
\text { of agricultural science and } \\
\text { technology promotes the } \\
\text { transformation from traditional } \\
\text { agriculture to modern agriculture. }\end{array}$ & \\
\hline & $\begin{array}{l}\text { O3: The development of urban } \\
\text { economy is conducive to the } \\
\text { establishment of modern } \\
\text { agricultural management system. }\end{array}$ & \\
\hline
\end{tabular}

\subsubsection{Strengths}

S1: Excellent ecological environment and rich natural resources.

Compared with the crowded and noisy city, the countryside has fresh air and natural agricultural landscape. In the modern society where industrial pollution is increasingly serious, rural pastoralism has become a new life aspiration.

China's rural areas have rich natural resources, such as water resources, energy resources, and biological resources, which can provide a good foundation for the development of various industries.

S2: Rural civilization with a long history.

Cities have existed in China for only a few hundred years, while vast villages have existed in China for thousands of years. This gives Chinese villages the historical and cultural background of development, and forms a unique rural culture, farming culture and folk culture. Some excellent cultural traits are preserved in the countryside, such as honesty, diligence and unity.

S3: Great potential for rural economic development.

In recent years, tens of millions of poor people in China have been lifted out of poverty. These people's burdens in medical care, health care, old-age care, education, etc. have been alleviated, and their net increase in economic income can be transformed into production and living consumption, which has become a strong driving force for the domestic market.

\subsubsection{Weaknesses}

W1: Development of modern agriculture is sluggish, economic structure changes lag.

China's agricultural modernization is seriously lagging behind the process of urbanization and industrialization. Compared with the proportion of agricultural added value in developed countries, the proportion of China's agricultural added value fell below $10 \%$ for the first time in 2009 , and the ratio has only decreased by 1.23 
percentage points in the next eight years. According to this speed, the proportion of China's agricultural added value reduced to $5 \%$ needs to wait until 2041. The fluctuation range of urban-rural binary contrast coefficient in China from 1978 to 2016 is $0.145-0.259$, and the strength of urban-rural dual economic structure is at a high level in the world. In other words, the urban-rural dual economic structure is still the main obstacle to the development of China's rural areas.

W2: The rural environment is prominent and the population is hollow.

From the perspective of agricultural non-point source pollution, China's grain production is highly dependent on agricultural chemicals such as fertilizers and pesticides. Long-term excessive use of pesticides, fertilizers and plastic film, as well as a large amount of waste generated by large-scale livestock breeding, has led to serious problems such as farmland consolidation, soil acidification and environmental pollution. The use of fertilizers and pesticides per hectare of cultivated land in China is still much higher than the world average. From the perspective of rural living environment, the problem of "dirty, messy and poor" in rural areas has been preliminarily solved in recent years. However, due to the long-term lack of investment in rural construction, the rural living environment is still poor.

At the same time, with the rapid progress of urbanization, a large number of rural labor force, especially middle-aged men, went to work in cities, and most of them settled in cities, which led to the rapid loss of rural population. The main people still living in the countryside today are the elderly, women and children. According to the statistics released by the Ministry of Education of China, the number of left-behind children in rural areas was 15.5056 million in 2017.

W3: The agricultural labor force has a low level of human capital, and it is difficult for farmers to increase their income.

The human capital investment of rural labor force is at a low level. Due to the chronic shortage of public services such as education and medical care, the overall low level of human capital of Chinese farmers has not been fundamentally changed. In China, $91.8 \%$ of agricultural workers have junior high school education or below, and no more than $7 \%$ in western and northeastern regions have received high school education or above. This is a major issue that must be faced in the process of agricultural and rural modernization and rural economic transformation and upgrading (Note 2).

\subsubsection{Opportunities}

01: The country's comprehensive strength has increased, and the government has formulated a " rural revitalization strategy".

China's financial strength and overall national strength are growing, and the policy of benefiting farmers is continuously increasing. In 2018, China's poverty alleviation expenditure reached 477 billion yuan, an increase of $46.6 \%$, nearly 160 billion yuan more than in 2017 . Among them, the central government's special poverty alleviation funds totaled 106.1 billion yuan, an increase of $23.2 \%$. At the end of 2018, the number of rural poor in the country decreased from 98.99 million at the end of 2012 to 16.6 million. The incidence of poverty dropped from $10.2 \%$ in 2012 to $1.7 \%$, a cumulative decrease of $8.5 \%$.

China actively faces the problem of the huge gap between urban and rural development, and attaches great importance to the good functions of rural areas in economic, political, cultural, social and ecological aspects. In order to promote rural development, China has formulated the "rural revitalization strategy". At present, China's rural areas are actively promoting supply-side structural reforms. The combination of traditional agriculture and modern agriculture and the deep integration of the first, second and third industries have made it possible for the rural areas to achieve industrial upgrading and promote economic development.

O2: The tremendous development of agricultural science and technology promotes the transformation from traditional agriculture to modern agriculture.

With the further deepening of agricultural research, agricultural production resources have been rationally distributed. While improving the efficiency of agricultural production, it also increases the utilization rate of agricultural production factors with the help of scientific research. Scientific research can better serve agriculture and help to achieve the scale of the agricultural economy. All kinds of small and medium-sized agricultural enterprises have been effectively developed in the welfare of scientific and technological progress, and have contributed to the overall advancement of China's agricultural economy. At the same time, advanced machines replace some of the manpower for agricultural production. The replaced labor force receives professional training to transfer labor to other places and carry out high-level agricultural-related work, thereby increasing agricultural productivity. 
O3: The development of urban economy is conducive to the establishment of modern agricultural management system.

China's employment elasticity (the ratio of employment growth rate to economic growth rate) is much lower than that of developed countries' rapid economic growth, which indicates that China's urban employment potential is still very large. According to purchasing power parity, China's per capita income level is about $1 / 5$ of that of the United States. This shows that the labor price advantage is still significant, and the potential for continued expansion of the urban economy is huge. From the perspective of labor supply, the space for rural labor release is still very large: China's agricultural added value accounts for less than $10 \%$ of the total GDP, and the proportion of labor used (calculated according to labor time and technology constant assumptions) is about 23\%; It is expected that the goal of equal income between farmers' family farming and urban household income will be achieved around 2035. At that time, China only needs about 30 million professional farmers, accounting for about 6\% of the total number of households in the country (Dang, G., 2015). The rapid development of urban economy has greatly improved the ability of cities to absorb rural labor transfer, and is conducive to the establishment of modern agricultural management system.

\subsubsection{Threats}

T1: The international competition that agriculture faces is more and more intense.

China's agriculture has entered the era of high cost. From 2006 to 2013, the annual growth rate of production cost of rice, wheat, corn, cotton and soybean in China was $11 \%, 11.6 \%, 11.6 \%, 13.1 \%$ and $12 \%$ respectively. At the same time, China's import tariff on agricultural products is only $15.2 \%$ on average, which is $1 / 4$ of the world level. Moreover, China has abandoned the special safeguard mechanism of trade, and there is still a big gap between domestic agricultural subsidies and developed countries. In addition, falling international shipping costs and the rising value of the yuan in recent years have helped widen price differentials at home and abroad.

T2: China's slowing economic growth has had a big impact on farmers' incomes.

The farmer's income has four parts: household operating income, wage income, property income and transfer income. Among them, household management income and wage income are the main factors supporting the growth of farmers' income.

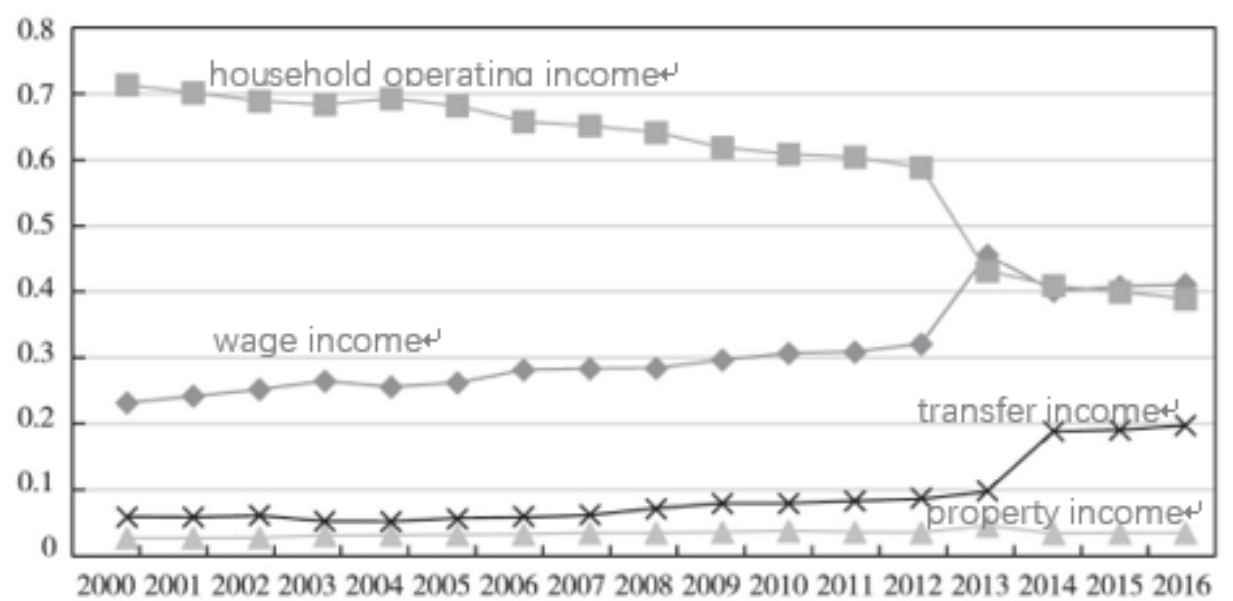

Figure 1. Changes in the proportion of Chinese farmers' income components from 2000 to 2016

In recent years, the price of China's grain market has been sluggish for a long time, while the cost of planting has been increasing. Growing grain is no longer able to bring enough net profit to farmers. In Figure 1, it can be clearly observed that the proportion of household operating income has continued to decline. The increase in wage income is positively related to the level of regional economic development. Therefore, the slowdown in economic growth will put pressure on the growth of total employment of farmers. Farmers are mainly engaged in labor-intensive work in the construction industry or other low-end industries. Faced with the downward pressure on the domestic economy, the employment rate of migrant workers may decline. Even if they are not unemployed, wage increases will be constrained. Second, compared with the increasing number of university 
graduates and urban reemployed people, farmers are in a weak position in the job market because of their low overall quality. The poor employment stability of farmers is also not conducive to the steady growth of their wage income.

\subsection{AHP Analysis}

In the established hierarchical structure, each factor and the next element under the control of the factor constitute a subsystem, and each element in the subsystem constructs several judgment matrices. Then establish the element two-two importance comparison judgment matrix. The degree of importance is assigned by 1-9. The importance scale and meaning are shown in Table 2.

Table 2. Meaning of the importance scale

\begin{tabular}{ll}
\hline Importance scale & Meaning \\
\hline 1 & Element $\mathrm{i}$ and element $\mathrm{j}$ have the same importance to the last factor. \\
& Element $\mathrm{i}$ is slightly more important than element $\mathrm{j}$. \\
3 & Element $\mathrm{i}$ is more important than element $\mathrm{j}$. \\
7 & Element $\mathrm{i}$ is much more important than element $\mathrm{j}$. \\
9 & Element $\mathrm{i}$ is extremely more important than element $\mathrm{j}$. \\
$2,4,6,8$ & The importance of element $\mathrm{i}$ and element $\mathrm{j}$ is between $2 \mathrm{n}-1$ and $2 \mathrm{n}+1$. \\
& $\begin{array}{l}\text { If the ratio of the importance of element } \mathrm{i} \text { to element } \mathrm{j} \text { is } \mathrm{a}_{\mathrm{ij}} \text {, then the ratio of } \\
\text { the importance of element } \mathrm{j} \text { to element } \mathrm{i} \text { is } \mathrm{a}_{\mathrm{ji}}=1 / \mathrm{a}_{\mathrm{ij}} .\end{array}$ \\
\end{tabular}

By using the value of the consistency ratio CR calculated by the AHP method, it is judged whether the expert assignment is reasonable and the calculation process is correct. It is reasonable if $\mathrm{CR}=\mathrm{CI} / \mathrm{RI} \leq 0.1$.

Table 3. RI values

\begin{tabular}{cccccccccccc}
\hline $\mathrm{n}$ & 1 & 2 & 3 & 4 & 5 & 6 & 7 & 8 & 9 & 10 & 11 \\
\hline R.I & 0 & 0 & 0.58 & 0.90 & 1.12 & 1.24 & 1.32 & 1.41 & 1.45 & 1.49 & 1.51 \\
\hline
\end{tabular}

\subsubsection{China's Rural Development Strategy Selection Hierarchy}

Decompose the strengths, weaknesses, opportunities and threats of China's rural development into different variables to form a hierarchical structure of China's rural development strategy. 


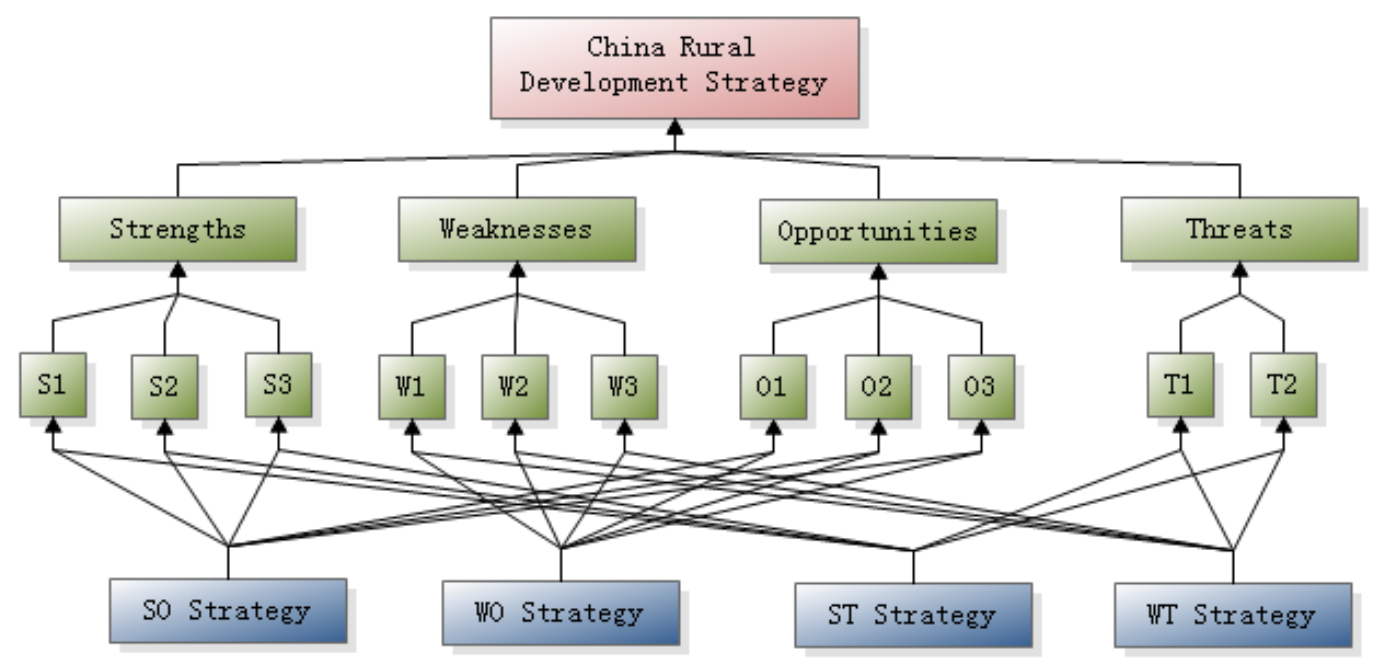

Figure 2. Hierarchical structure of China's rural development strategy selection

\subsubsection{Building a Judgment Matrix and Determining Weights}

25 industry experts were selected to evaluate the SWOT factors of Chinese rural development in accordance with the scale 1-9 by questionnaire survey. Finally, the Chinese rural development judgment matrix A, the superior judgment matrix $\mathrm{S}$, the inferior judgment matrix $\mathrm{W}$, the opportunity judgment matrix $\mathrm{O}$, and the threat judgment matrix T are formed (Li, Y., \& Liu, X., 2019).

$$
\begin{aligned}
\mathrm{A} & =\left(\begin{array}{cccc}
1 & 1 & 1 / 3 & 4 \\
1 & 1 & 1 / 4 & 4 \\
3 & 4 & 1 & 8 \\
1 / 4 & 1 / 4 & 1 / 8 & 1
\end{array}\right), \mathrm{S}=\left(\begin{array}{ccc}
1 & 3 & 1 \\
1 / 3 & 1 & 1 / 3 \\
1 & 3 & 1
\end{array}\right), \mathrm{W}=\left(\begin{array}{ccc}
1 & 5 & 3 \\
1 / 5 & 1 & 1 / 2 \\
1 / 3 & 2 & 1
\end{array}\right) \\
\mathrm{O} & =\left(\begin{array}{ccc}
1 & 4 & 7 \\
1 / 4 & 1 & 3 \\
1 / 7 & 1 / 3 & 1
\end{array}\right), \mathrm{T}=\left(\begin{array}{cc}
1 & 1 / 3 \\
3 & 1
\end{array}\right)
\end{aligned}
$$

\subsubsection{Consistency Test of Each Layer Factor}

The maximum eigenvalues and eigenvectors of the five judgment matrices are calculated and the consistency test is performed. See Table 4. The CR values of the five judgment matrices are all less than 0.1 , and all pass the consistency test. The eigenvector corresponding to the largest eigenvalue, the weight vector, is the importance of the layer element to the element above.

Table 4. Factors affecting rural development in China

\begin{tabular}{cccc}
\hline $\begin{array}{c}\text { Judgment } \\
\text { matrix }\end{array}$ & the weight vector & $\begin{array}{c}\text { The maximum } \\
\text { eigenvalues }\end{array}$ & CR \\
\hline $\mathrm{A}$ & $(0.1952,0.1830,0.5668,0.0549)$ & 4.0549 & 0.0172 \\
$\mathrm{~S}$ & $(0.4286,0.1429,0.4286)$ & 3.0000 & 0.0000 \\
$\mathrm{~W}$ & $(0.6479,0.1222,0.2299)$ & 3.0037 & 0.0036 \\
$\mathrm{O}$ & $(0.7014,0.2132,0.0853)$ & 3.0326 & 0.0313 \\
$\mathrm{~T}$ & $(0.2500,0.7500)$ & 2.0000 & 0.0000 \\
\hline
\end{tabular}

\subsubsection{Combination Weights and Weighted Scores}

Calculate the relative importance of all indicators to the overall goal and perform a hierarchical overall ranking. 
Expert scoring was performed according to the Delphi method (scores were -4, -3, -2, -1, 0, 1, 2, 3, 4). Strengths and opportunities give positive scores, disadvantages and threats give negative scores. The greater the absolute value of its final weighted score, the greater its intensity.

Table 5. Combination weights and weighted scores of China's rural development influencing factors

\begin{tabular}{|c|c|c|c|c|c|c|c|}
\hline Target & $\begin{array}{c}\text { Criteria } \\
\text { layer }\end{array}$ & $\begin{array}{c}\text { Weight } \\
\text { between } \\
\text { groups }\end{array}$ & $\begin{array}{c}\text { Indicator } \\
\text { layer }\end{array}$ & $\begin{array}{l}\text { Group } \\
\text { weight }\end{array}$ & $\begin{array}{c}\text { Combination } \\
\text { weight }\end{array}$ & $\begin{array}{l}\text { Expert } \\
\text { score }\end{array}$ & $\begin{array}{l}\text { Weighted } \\
\text { score }\end{array}$ \\
\hline \multirow{11}{*}{$\begin{array}{l} \\
\\
\end{array}$} & \multirow[t]{3}{*}{$S$} & \multirow[t]{3}{*}{0.1952} & S1 & 0.4286 & 0.0837 & 4 & 0.3348 \\
\hline & & & S2 & 0.1429 & 0.0279 & 3 & 0.0837 \\
\hline & & & S3 & 0.4286 & 0.0837 & 4 & 0.3348 \\
\hline & \multirow[t]{3}{*}{ W } & \multirow[t]{3}{*}{0.1830} & W1 & 0.6479 & 0.1186 & -4 & -0.4744 \\
\hline & & & W2 & 0.1222 & 0.0224 & -3 & -0.0672 \\
\hline & & & W3 & 0.2299 & 0.0421 & -3 & -0.1263 \\
\hline & \multirow[t]{3}{*}{$\mathrm{O}$} & \multirow[t]{3}{*}{0.5668} & O1 & 0.7014 & 0.3976 & 4 & 1.5904 \\
\hline & & & $\mathrm{O} 2$ & 0.2132 & 0.1209 & 4 & 0.4836 \\
\hline & & & $\mathrm{O} 3$ & 0.0853 & 0.0484 & 2 & 0.0968 \\
\hline & \multirow[t]{2}{*}{$\mathrm{T}$} & \multirow[t]{2}{*}{0.0549} & $\mathrm{~T} 1$ & 0.2500 & 0.0137 & -1 & -0.0137 \\
\hline & & & $\mathrm{T} 2$ & 0.7500 & 0.0412 & -2 & -0.0824 \\
\hline
\end{tabular}

\subsection{SWOT Quadrant Strategic Choice}

Total strength intensity: $S_{a}=\sum S_{i} / n_{s}=0.2511$

Total weakness intensity: $W_{a}=\sum W_{i} / n_{w}=-0.2226$

Total opportunity intensity: $O_{a}=\sum O_{i} / n_{o}=0.7236$

Total threat intensity: $T_{a}=\sum T_{i} / n_{t}=-0.0481$

The quadrants are established with the strengths, weaknesses, opportunities and threats of China's rural development. The total strength intensity (Sa), total weakness intensity (Wa), total opportunity intensity $(\mathrm{Oa})$ and total threat intensity (Ta) are coordinate positioning, and the four-point connection is developed as a strategic quadrant. In this way, the strategic center of gravity coordinates, strategic azimuth, and strategic positive, negative, and intensity coefficients of the strategic quadrilateral are calculated.

Strategic center of gravity coordinates: $P(X, Y)=(0.0071,0.1689)$

Strategic azimuth: $\theta=\arctan (Y / X)=88^{\circ}$

Positive strategic strength: $U=O \cdot S=0.7236 \times 0.2511=0.1817$

Strategic negative strength: $V=T \cdot W=0.0481 \times 0.2226=0.0107$

Strategic strength factor: $\rho=U /(U+V)=2.2287 / 2.3881=0.9444$ 


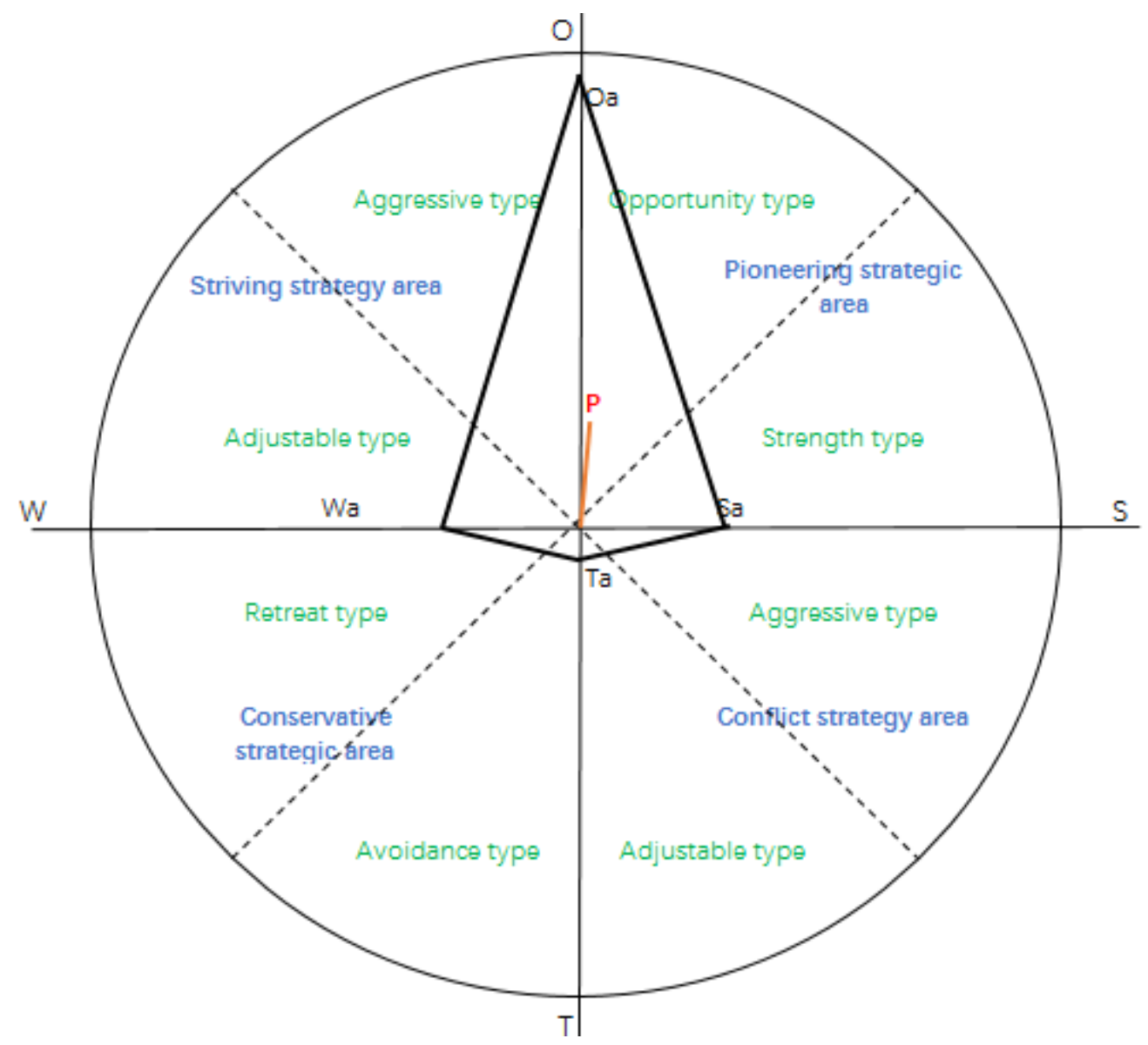

Through SWOT quantitative analysis of China's rural development can be found that the development strategic positioning in the first quadrant $\left(45^{\circ}, 90^{\circ}\right)$, located in the pioneering and directives, should take the opportunity to type development strategy should be taken. It means that we should grasp the state's policy support and guidance, rely on the advancement of agricultural science and technology, and actively develop modern agriculture, improve the overall quality of the labor force, and improve the rural ecological environment based on the advantages of enriching natural resources and characteristic cultural resources.

\section{Conclusion \& Suggestion}

\subsection{Conclusion}

Through SWOT qualitative analysis and SWOT-AHP quantitative analysis of rural development in China, the results show that for rural development: opportunity > advantage > disadvantage > threat. The influence of each factor on its strengths, weaknesses, opportunities and threats is also different. Rich natural resources and great potential for economic development (0.0837) are the most advantageous conditions for rural development. The weak modern agricultural development and the economic structure with delayed transition $(0.1186)$ are the main disadvantages affecting the development of rural China. "Rural revitalization strategy" (0.3976) is a significant opportunity for China's rural development. But it also has to deal with the greater challenge to China's income due to the slowdown in China's economic growth (0.0412).

\subsection{Suggestion}

4.2.1 Grasping the Strategic Opportunity of "Revitalization of the Countryside" and Promoting Modern Agricultural Construction From Various Aspects

With the deepening of the rural revitalization strategy, the state's support for agriculture and rural areas will continue to increase.

(1) In terms of development concepts, it is advisable to take advantage of the reform of state institutions to highlight the concept of large-scale agriculture and emphasize the development of multifunctional agriculture. In this way, the agricultural industry will be shifted from increasing production to improving 
quality and efficiency.

(2) In terms of spatial layout, it should be based on resource endowment, location conditions and urbanization development needs. Non-agricultural industries such as processing and circulation of agricultural products based on agriculture should be developed according to local conditions. This will promote the coordinated development of industry and development and the integration of the first, second and third industries (Chen, X., \& Cheng, X., 2018).

(3) In terms of development approaches, a policy system of introduction and support should be established in accordance with market rules. Equal emphasis on industry, employment, entrepreneurship, etc., while promoting urban and rural production factors from the one-way flow of agriculture to non-agricultural industries to the two-way free flow of urban and rural factors. In this way, we will encourage the orderly development of social capital and improve the modern agricultural industrial system, production system and management system.

(4) In terms of institutional mechanisms, it is necessary to implement the agricultural functional zoning system and scientifically calculate the multi-functional value of agricultural and rural areas. Second, the government needs to introduce a negative list of agricultural industry investment to showcase the functions of production, ecology, culture, leisure, and employment carried by agricultural villages. In this way, the coordination between different main objectives and cost-effectiveness of government, enterprises and farmers is realized.

(5) In terms of government management, it is urgent to formulate coordinated and comprehensive departmental and regional policies to fundamentally rationalize the relationship between the government and the market. Improve the efficiency of agricultural support by strengthening the pertinence, synergy and linkage of policies.

\subsubsection{Pay Attention to the Cultivation of Labor Quality and Improve the Level of Rural Human Capital}

The main way of investing in human capital is to invest in education. The government must play the main role of investment in education. By expanding the financial influence, the rural education funds that guarantee investment can be implemented and the burden of education for farmers can be reduced. At the same time, government departments must improve basic education. By improving the conditions for running schools in rural areas and improving the income and welfare of teachers in rural areas, a large number of outstanding teachers are attracted to rural education. The society must pay attention to the development of rural vocational education. Due to the serious loss of high-quality labor in rural areas, investing in rural vocational education is an effective way to improve the level of rural labor. Pay attention to the mental state of rural labor groups, enrich the spiritual and cultural life in rural areas, and let the workers in rural areas have a good attitude and improve the construction of rural entertainment and cultural facilities, such as the construction of small squares and sports fields.

\subsubsection{Cultivate the Concept of Ecological Civilization and Build a Green Production Lifestyle}

Continuously optimize and improve rural infrastructure conditions, and transform agricultural production and rural economic growth models from traditional extensive growth to intensive growth. Through the development of scientific research, improve the efficiency and quality of agricultural production, so as to promote the transformation of rural production and lifestyle and realize the green transformation of rural production and lifestyle. On the one hand, farmers must build green production methods. Further adjust and optimize the agricultural structure and enhance the comprehensive agricultural production capacity. In the process of realizing agricultural modernization, with the help of science and technology and innovation, promote low-carbon development and green transformation of agriculture. While achieving economic growth, we should conserve resources and protect the environment (Cui, L., \& Cui, N., 2019). On the other hand, farmers have to form a green lifestyle. In real life, rural areas basically discharge domestic sewage and domestic garbage in an extensive way, which causes damage to the rural ecological environment. It is necessary to build a simple and modest lifestyle and explore and practice green living. Through the transformation of lifestyles, it will help the development of green economy in rural areas (Yu, Y., Qi, S., \& Gong, J., 2019).

\section{References}

Chen, X., \& Cheng, C. (2018). The Three-product Integration Path of Rural Revitalization Strategy: Logical Inevitability and Empirical Judgment. Agricultural Economics Issues, (11), 91-100.

Cui, L., \& Cui, N. (2019). Exploration of the Path of Rural Low-carbon Economy Development from the Perspective of Ecological Civilization. Ecology and Economy, 35(3), 216-219. 
Dang, G. (2015). Challenges and Opportunities under the New Situation of Rural Development. Guangming Daily, January 17, (11).

Li, Y., \& Liu, X. (2019). Study on the Development of Ecotourism in Forest Park Based on SWOT-AHP Model— - Taking Beijing Olympic Forest Park as an Example. Forestry Economics, 41(1), 71-75, 111.

Yu, Y., Qi, S., \& Gong, J. (2019). Exploration of the synergy path of rural industrial revitalization and spatial planning based on ecological adaptability. Ecology and Economy, 35(3), 224-229.

\section{Notes}

Note 1. Administrative Division of the People's Republic of China 2017.

Note 2. China Rural Development Report, Rural Development presents five major characteristics. Modern City Research, 2018(09), 131.

\section{Copyrights}

Copyright for this article is retained by the author(s), with first publication rights granted to the journal.

This is an open-access article distributed under the terms and conditions of the Creative Commons Attribution license (http://creativecommons.org/licenses/by/4.0/). 